\title{
Erosion Control Using Modified Soils
}

\author{
James T. Kidd ${ }^{1}$, Chung R. Song ${ }^{2}$, Ahmed Al-Ostaz ${ }^{2}$, Alexander H.-D. Cheng ${ }^{2}$ and Wongil Jang ${ }^{1}$ \\ ${ }^{1}$ CE Tech. Lab 107, University of Mississippi, University, MS 38677, USA \\ ${ }^{2}$ University of Mississippi, University, MS 38677, USA
}

\begin{abstract}
As a result of Hurricane Katrina, many sections of the flood protection systems in New Orleans were eroded due to plunging water, and sections of flood walls were determinately damaged. Therefore, mitigating this type of erosion and failure is necessary for counteracting similar catastrophic events. This study evaluated the method to mitigate erosion due to plunging water by strengthening the soil with ground modification. The Vetiver plant and Polyhedral Oligomeric Silsesquioxanes (POSS) were the two main ground modifiers used in this test. Test results showed that both POSS and the Vetiver were effective in reducing erosion. POSS showed good erosion resistance with good applicability to field soils; Vetiver showed higher resistance to erosion by plunging water, but required time to achieve a well established root/stem system.
\end{abstract}

\section{Introduction}

Erosion caused by plunging water from the floodwalls during Hurricane Katrina caused extensive damage to the levee systems in New Orleans, Louisiana. Typical runoff erosion is initiated when the flow direction is parallel to the ground surface. Plunging water causes impact erosion which is initiated when the flow is almost vertical to the ground, and erosion behavior of soils may be different.

New Orleans is located on the Gulf Coast of Louisiana and is surrounded almost entirely by water: the Gulf of Mexico, the Mississippi River, Lake Pontchartrain, and numerous canals. Also, a substantial portion of New Orleans is located approximately two meters below sea level as shown in Fig. 1, and all rainwater must be pumped up to the canals, Mississippi River, or lakes. Due to these conditions, during times of excess rainfall coupled with failure of pumping stations, New Orleans may experience severe flooding; that actually happened during Hurricane Katrina.

Trying to cope with rising flood waters, New Orleans has implemented several techniques to prevent flood damage including elevated levees and flood walls.

One method of prevention is to raise the levee height, but this can be accomplished only by an accompanying process of widening the levee base. This may interfere with the private land ownership in urban areas. Therefore, most levee systems in urban areas cannot be raised above their current height; concrete flood walls are constructed on the top of the levees instead.

Hurricane Katrina made landfall on August 29, 2005 as a category three hurricane with peak wind speeds sustained at $125 \mathrm{mph}$, causing roughly two billion dollars worth of damage to the infrastructure [IPET, 2007]. The storm surge that accompanied Hurricane Katrina was roughly 3.5-4.5 meters high. In addition to the storm surge, rainfall was estimated to be at $36 \mathrm{~cm}$ over a 24-hour period. However, these are only estimates because most of the instruments used to measure storm surge and rainfall were destroyed [IPET, 2007]. Eighty percent of the New Orleans metropolitan area was flooded [IPET, 2007].

New Orleans hurricane protection systems were not designed to accommodate such high water levels. Water levels in canals exceeded the height of the flood walls by 30 to $60 \mathrm{~cm}$, and overtopping water impacted the levee soil with approximate velocity $6 \mathrm{~m} / \mathrm{sec}$. Approximately 50 major breaches occurred in the hurricane protection system; 46 of which were the result of overtopping water which caused the soil erosion that eventually led to the failure of many floodwalls [IPET, 2007]. Soil 


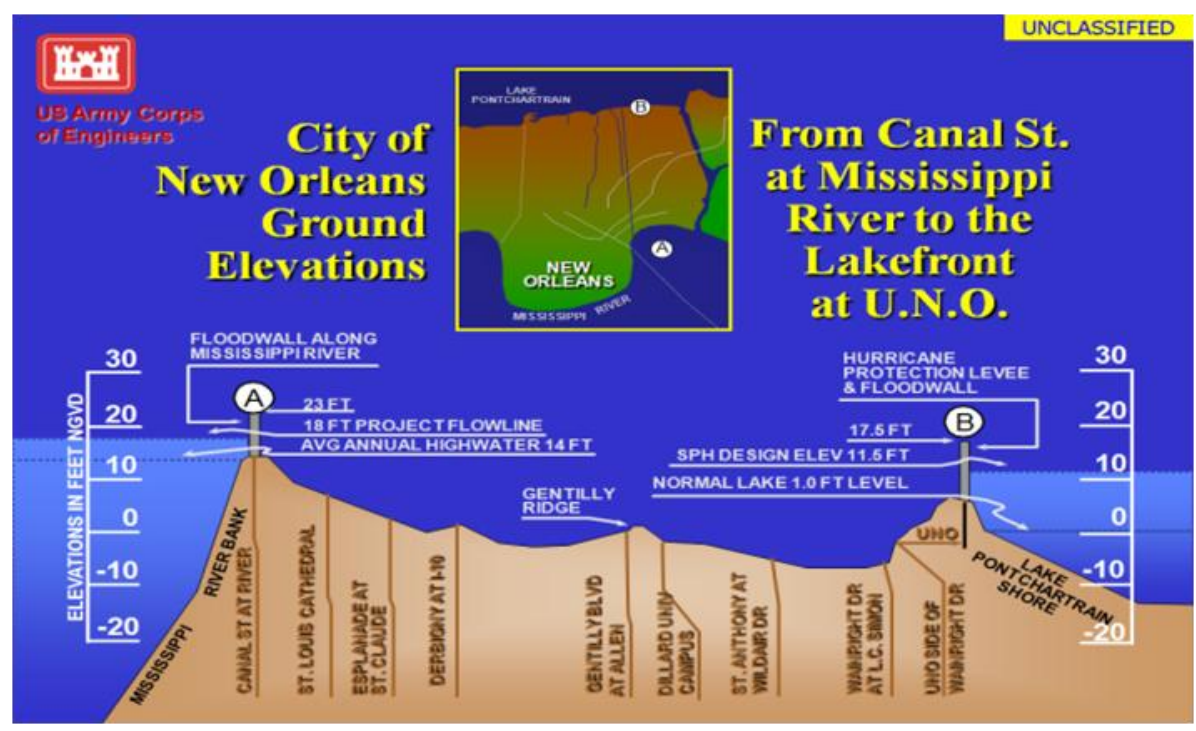

Fig. 1 Representative Cross Section of New Orleans

compositions on overtopping breached area are not well known. But it is known that the fat clay levee in Orleans Canal was overtopped but not failed. On the other hand, sandy (SM) levee in IHNC (Inner Harbor Navigation Channel) was overtopped and experienced wide spread failure [IPET, 2007].

There are several factors that influence the erosion of soil which include: the applied shear stress, clay content, soil temperature, water temperature, unit weight, water content, and the undrained shear strength. [Briaud et al., 1999]. Also, the shear strength of soil is increased when: unit weight is increased, clay content increases, undrained shear strength increases, and void ration decreases. [Briaud et al., 2001]. However, reliable relationships between the erosion process and soils properties are not reported yet.

This study primarily focuses on preventing or reducing erosion from overtopping water through ground modification. In order to do this, the bare (untreated) soil samples were used as a reference soil. These were bare soils that have no chemicals added or additional enhancements that may increase erosion resistance of the soil. All the soil samples that have been tested are a mixture of fine and course soils taken from a quarry site in New Orleans and mixed in the lab based on material specification of levees [Vroman, 2008].

\section{Test Samples}

The fine grained soil was classified as $\mathrm{CH}$ or $\mathrm{CL}$ with the percentage passing the \# 200 sieve about $80 \%$. Course grained soil was classified as SM with 4.5\% passing the \#200 sieve. For detailed sample mixing and preparation procedures please refer to Song et al. (2009). Four different mixtures of fine and course soil are used in testing: 50/50, 57/43, $65 / 35$, and $73 / 27$ (with $\%$ of fines being the first number and course materials following respectively). Four different intended degrees of compaction are also tested: $95 \%, 91 \%, 87 \%$, and $83 \%$, this is assuming a $\pm 2 \%$ tolerance. With four mixtures and four degrees of compaction, this gives a total of sixteen different combinations of soil samples as shown in Table 1.

The ground modifiers chosen for this study were based on environmental impact and applicability. POSS is a silicone based solution which is very similar to natural geo-materials and USDA approved. Vetiver is a green solution, so it is environmentally safe. In addition, both can be applied with relative ease. However, there are ground modifiers such as soil-cement and geotextile fibers. These were not chosen for this study due to the fact that they may cause environmental issues for the case of soil-cement and need elaborated mixing process in the field for the case of geotextile fibers.

For a chemical ground modifier, Polyhedral Oligomeric Silsesquioxanes (POSS) is used. POSS is a liquid chemical poured onto soil samples to reduce erosion. There are two different POSS consolidates used in the erosion testing: SO1455 (3\% TriSilonollsooctyl POSS $\mathrm{C}_{56} \mathrm{H}_{122} \mathrm{O}_{12} \mathrm{Si}_{7}$ ) and $\mathrm{SO} 1458$ (3\% TriSilonalPhenyl POSS $\quad \mathrm{C}_{42} \mathrm{H}_{38} \mathrm{O}_{12} \mathrm{Si}_{7}$ ) [www.hybridplastics.com].

After completion, the samples treated with POSS were cured and dried at room temperature for two weeks. This process allows the POSS ample time to penetrate into the soil samples and interact with the soil. 
Table 1 Basic Soil Properties of Soil Samples [Jang et al., 2010]

\begin{tabular}{|c|c|c|c|c|c|}
\hline $\begin{array}{l}\text { oil } \\
\text { Identification }\end{array}$ & $\begin{array}{l}\text { Degree } \\
\text { of } \\
\text { Compa } \\
\text { ction } \\
(\%)\end{array}$ & $\begin{array}{c}\gamma_{\mathrm{sat}} \\
\left(\frac{\mathrm{kN}}{\mathrm{m}^{3}}\right)\end{array}$ & $\begin{array}{c}\gamma_{\mathrm{d}} \\
\left(\frac{\mathrm{kN}}{\mathrm{m}^{3}}\right)\end{array}$ & $\mathrm{e}$ & $\begin{array}{l}\mathrm{Sr} \\
(\%)\end{array}$ \\
\hline \multirow{4}{*}{$\begin{array}{l}\frac{\text { F50S50 }}{\text { Clay } 15 \%} \\
\text { Silt } 35 \% \\
\text { Sand } 50 \%\end{array}$} & 83 & 16.5 & 14.1 & .96 & 48 \\
\hline & 87 & 17.1 & 14.6 & .88 & 52 \\
\hline & 92 & 18.3 & 15.7 & .86 & 54 \\
\hline & 99 & 19.5 & 16.7 & .74 & 62 \\
\hline \multirow{4}{*}{$\begin{array}{l}\frac{\text { F57S43 }}{\text { Clay } 18 \%} \\
\text { Silt } 40 \% \\
\text { Sand } 42 \%\end{array}$} & 85 & 16.8 & 14.2 & .9 & 54 \\
\hline & 88 & 17.4 & 14.7 & .83 & 58 \\
\hline & 92 & 18.1 & 15.4 & .76 & 64 \\
\hline & 97 & 19.1 & 16.2 & .67 & 73 \\
\hline \multirow{4}{*}{$\begin{array}{l}\text { F65S35 } \\
\text { Clay 20\% } \\
\text { Silt } 45 \% \\
\text { Sand } 35 \%\end{array}$} & 84 & 17.9 & 14.5 & .9 & 57 \\
\hline & 87 & 17.8 & 14.9 & .84 & 61 \\
\hline & 91 & 19.1 & 16.2 & .78 & 65 \\
\hline & 97 & 20.2 & 17 & .62 & 82 \\
\hline \multirow{4}{*}{$\begin{array}{l}\text { F73S27 } \\
\text { Clay 23\% } \\
\text { Silt } 50 \% \\
\text { Sand } 27 \%\end{array}$} & 83 & 16 & 12.8 & 1.15 & 58 \\
\hline & 87 & 16.6 & 13.3 & 1.05 & 63 \\
\hline & 90 & 17.4 & 14 & .96 & 69 \\
\hline & 95 & 18.2 & 14.6 & .89 & 74 \\
\hline
\end{tabular}

For a biological ground modifier, the Vetiver plant (Chrysopogon zizanioides), a native of Southern Indian plant commonly referred to as Vetiver, is used. It is a very tall and dense grass that provides good stability, and it is sterile and non-invasive to other plants and animals. Vetiver is a very deeply rooted grass, and for this reason it has been used in Southern India for many years to prevent soil erosion. [Hengchaovanich, 1996], as shown in Fig. 2. The roots of Vetiver are thought to be able to penetrate into soils to a depth of 2-3 meters depending on the ground conditions [Hengchaovanich, 1996]. In addition, the reinforcing effect of this root system provides additional resistance to the shearing force of plunging water [Hengchaovanich, 1996].

POSS and Vetiver are the primary ground modifiers used in this research. The test results will be discussed further in this paper.

\section{Test Set Up and Procedure}

The University of Mississippi Erosion Test Bed (UMETB) is a combination of two tanks, five pumps, and pipes that were designed to mimic plunging water in New Orleans as shown in Fig. 3.

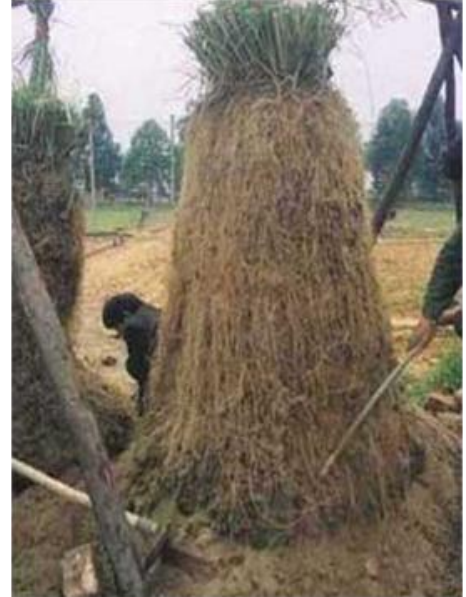

Fig. 2 Root system of Vetiver (www.vetiver.org)

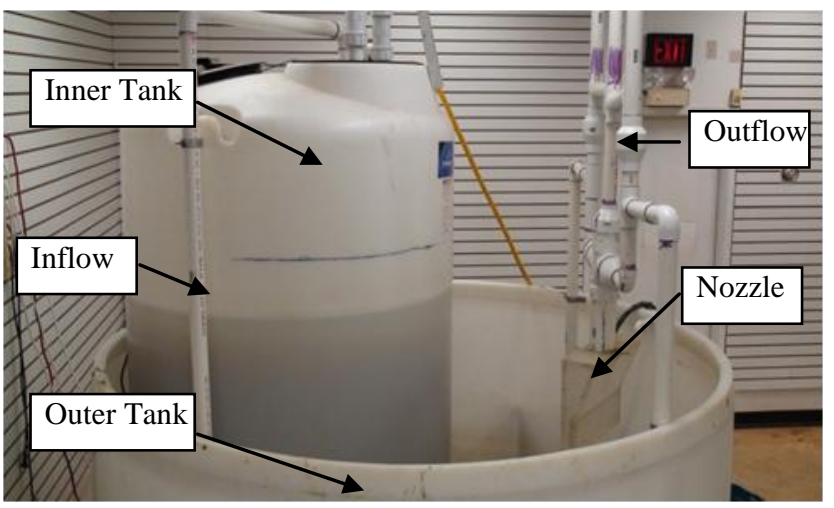

Fig. 3a Depiction of UMETB

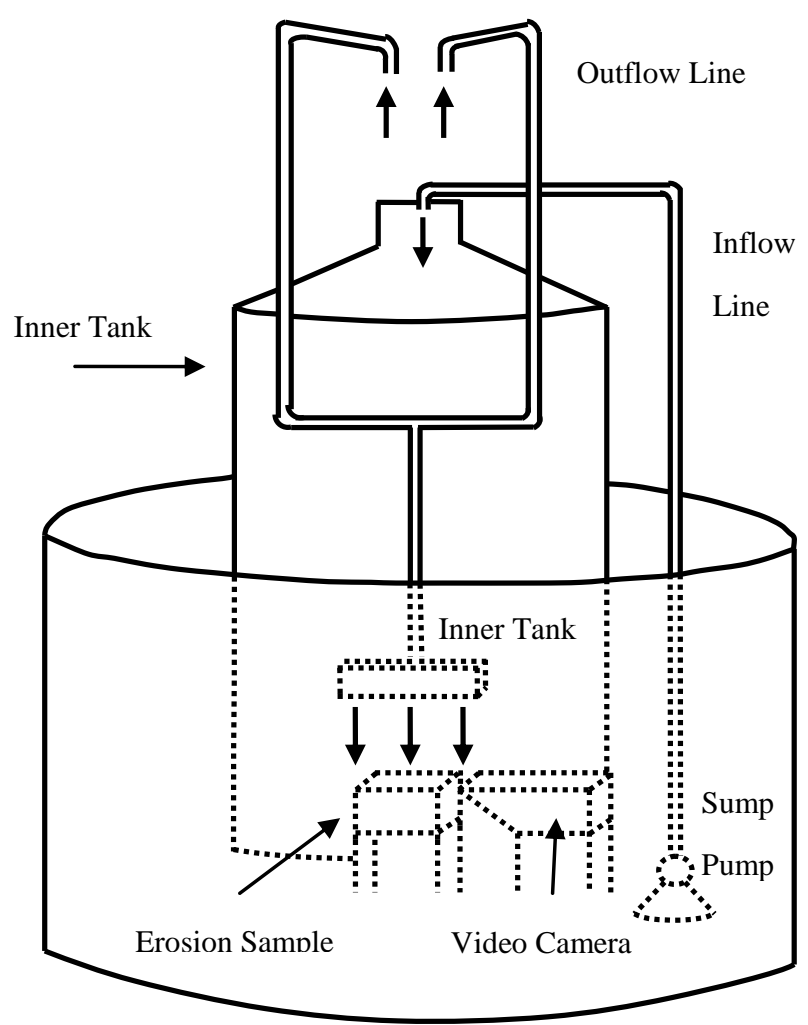

Fig. 3b Schematics of UMETB 


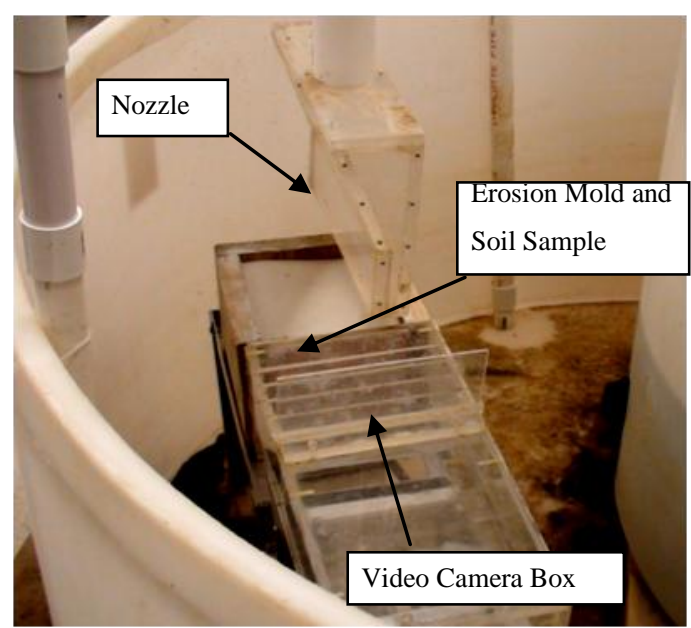

Fig. 4 Erosion testing mold

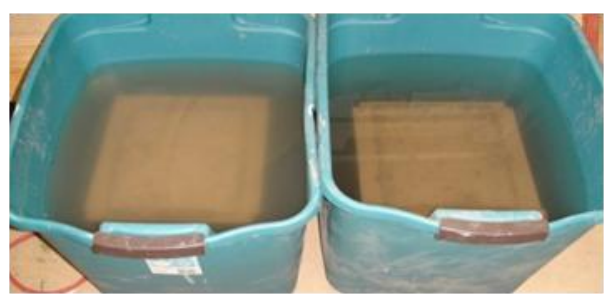

Fig. 5 Soil Sample after being submerged

The UMETB circulates water to into and out of an inner tank that in turn circulates water into and out of an outer tank. Water is pumped from the outer tank into the inner tank to fill the clean water in the inner tank; then clean water is pumped from the inner tank through a series of pipes directly to the nozzle as seen in Fig. 3b. In doing so, the water passes through a planar nozzle that is $.003 \mathrm{~m}$ thick that simulates water plunging over a flood wall. The velocity of this plunging water was controlled to be $6 \mathrm{~m} / \mathrm{s}$; this is about the same velocity of plunging water from the top of $1.8 \mathrm{~m}$ high flood walls which was the field conditions in New Orleans. The soil sample is placed in a metal holder in the bottom of the outer tank, and then the soil sample is moved directly next to the nozzle as seen in Fig. 4.

Soil samples are prepared as discussed the Test Samples chapter. Before any soil samples are made, the maximum dry density and optimum water content are measured for each mixture by the Standard Proctor Test (ASTM D698). The basic soil properties of each mixed and tested soil samples are shown in Table 1.

An erosion mold is a wooden container built of lumber and clear acrylic plate and designed to hold soil samples for testing [Jang et al., 2010]. The clear acrylic plate is used to view and record on video camera the erosion progress during test. The acrylic plate has a network of measured marks $(1 \mathrm{~cm} \times 1$ $\mathrm{cm}$ ) in order to accurately quantify erosion behavior on the video camera. After being built, the erosion molds are measured in order to obtain the volume Length $(.253 \mathrm{~m}) \times$ Width $(.20 \mathrm{~m}) \times$ Height $(.20 \mathrm{~m})=$ Volume $\left(.010537323 \mathrm{~m}^{3}\right)$. The soil samples are compacted to a specific degree of compaction in the erosion molds. Compaction is carried out in eight separate layers in order to obtain uniform compaction. Also, in order to mimic field compaction techniques, a gasoline powered tamper (Dynapac, LF45) was used. A coat of bentonite and water paste are applied to the inside of the erosion mold to decrease the amount of friction between the soil and the erosion mold during compaction (For further details on this technique, please see Jang et al., 2010).

During times of excess rainfall, flooding, and hurricanes, the soils surrounding the area may be soaked. To reproduce this condition, soil samples are completely submerged in water for 48 hours before testing, as shown in Fig 5. The water level was kept $.05 \mathrm{~m}$ above the sample in order not to apply too much water pressure to the samples. The dimensions of soil samples are taken before and after submersion in order to calculate changes in soil parameters such as void ratio and the degree of saturation.

\subsection{Testing Procedure}

The following test procedure is followed in this study.

1) Mount the erosion mold under the nozzle.

2) Set the video camera in front of the graduated acrylic plate to record the erosion profile with time.

3) Focus the video camera on the grid of the acrylic plate as shown in Fig. 4.

4) Turn on the five sump pumps (three of $1 / 3$ Horse Power for out-flow, two of $1 / 2$ Horse Power for in-flow) to circulate water from inner tank to outer tank via the nozzle so that it initiates the erosion on the soil sample surface.

5) Record the erosion process with the video camera.

6) Analyze the recorded video images with PMB (Picture Motion Browser) software and obtain erosion depth and lap time data.

\section{Analytical Equations for Erosion}

The excess stress concept [Hanson et al., 2002 modified from Stein et al., 1993], postulates that erosion of soil takes place if the effective shear stress from the moving fluid is higher than the 
critical (resisting) shear stress as shown in Eq. (1). Note that the erosion rate coefficient ( $k_{d}$ value), the difference between the effective shear stress and the critical shear stress, and the erosion time. This study computed $k_{d}$ so that erosion resistance of different soils may be compared quantitatively. This study, however, computed $k_{d}$ at each time step rather than computing a single average $k_{d}$ throughout the test. $\frac{d D}{d t}$ at a certain time is obtained from the test, $\tau_{o}$ and $\tau_{c}$ are obtained from tests and hydrodynamics. The calculation procedure of $k_{d}$ at time intervals is shown as follows.

$$
\frac{d D}{d t}=k_{d}\left(\tau_{o}-\tau_{c}\right)^{a}
$$

Where:

$D=$ erosion depth

$t=$ time

$k_{d}=$ erosion rate coefficient

$\tau_{o}=$ shear stress caused by flowing water

$\tau_{c}=$ critical shear stress

$a=$ constant

Eq. (1) is solved using dimensionless parameters as follows

When $D^{*} \leq D_{P}^{*}$

$$
T^{*}=D^{*}\left(\frac{D_{p}^{*}}{1-D_{P}^{*}}\right)^{a}
$$

When $D^{*} \geq D_{P}^{*}$

$$
T^{*}-T_{p^{-}}^{*}\left[-D^{*}-\ln \left(1-D^{*}\right)\right]_{D_{P}^{*}}^{D^{*}}=0
$$

Where:

$$
D^{*}=\text { normalized erosion depth }=\frac{D}{D_{e}}
$$

$D=$ erosion depth at a given time

$D_{e}=$ equilibrium erosion depth

$$
\begin{gathered}
D_{P}^{*}=\text { normalized depth of potential core }=\frac{D_{p}}{D_{e}} \\
\qquad D_{p}=\text { depth of potential core }=C_{d}^{2} y_{0}
\end{gathered}
$$

$$
C_{d}=\text { diffusion constant }=\sqrt{5.5(1+\cos \theta)}
$$

$\theta=$ impinging angle

$y_{o}=$ thickness of plunging water

$$
\begin{gathered}
T^{*}=\text { normalized time }=\frac{t}{T_{r}} \\
T_{r}=\text { reference time }=\frac{D_{e}}{k_{d} \tau_{c}} \\
T_{p}^{*}=\frac{\tau_{c}}{\tau_{e}}\left(\frac{\tau_{c}}{\tau_{e}-\tau_{c}}\right)^{a}, \text { Stein et al., } 1993(a=1) \\
\tau_{c}=\text { critical shear stress }=\frac{D_{p}}{D_{e}} \tau_{e}
\end{gathered}
$$

$$
\begin{gathered}
\tau_{o}=\text { effective shear stress }=C_{d}^{2} C_{f} \rho u_{0}^{2} \frac{y_{o}}{D} \\
C_{f}=\text { coefficient of friction }=\frac{0.0474}{2} R_{0}^{-\frac{1}{5}} \\
R_{0}=\text { Reynolds Number }=\frac{2 y_{0} u_{0}}{v} \\
u_{o}=\text { flow velocity of impinging water }
\end{gathered}
$$$$
v=\text { viscosity of water }
$$

This research focuses on the research conducted by Stein et al. (1993), Stein and Nett (1997) and Hanson et al. (2002). Their research proposed finding a constant $\mathrm{k}_{\mathrm{d}}$ value, which is a detachment coefficient. However, the Stein et al. and Hanson et al. approach was modified by Jang (2010) by using non constant $\mathrm{k}_{\mathrm{d}}$ incorporating the change of erosion coefficient due to the changes in soils strength, confining pressure, density and so on. This study adapted concepts by Jang, and the details of this approach can be found in Jang.

All of the values are known for the Eq. (3) through (14), except for $k_{d}, D_{e}$, and $\tau_{c}$. However, the final erosion depth $\left(D_{e}\right)$ can be found by plotting erosion depth vs. time and finding the ultimate value; then, the value for $\tau_{c}$ can be computed. After these two parameters are found, it is not difficult to use a spreadsheet to find the detachment coefficient $k_{d}$.

\subsection{Sample Calculation}

Sample calculation at time $=200$ seconds for POSS treated (SO1458) soil sample (F50S50 at 83\% Degree of Compaction) is conducted here. The correlating erosion depth for this time was found to be $5.5 \mathrm{~cm}$; this can be seen in Fig. 6. In order to perform these calculations it is assumed that the time to reach equilibrium depth $\left(D_{e}\right)$ is one hundred

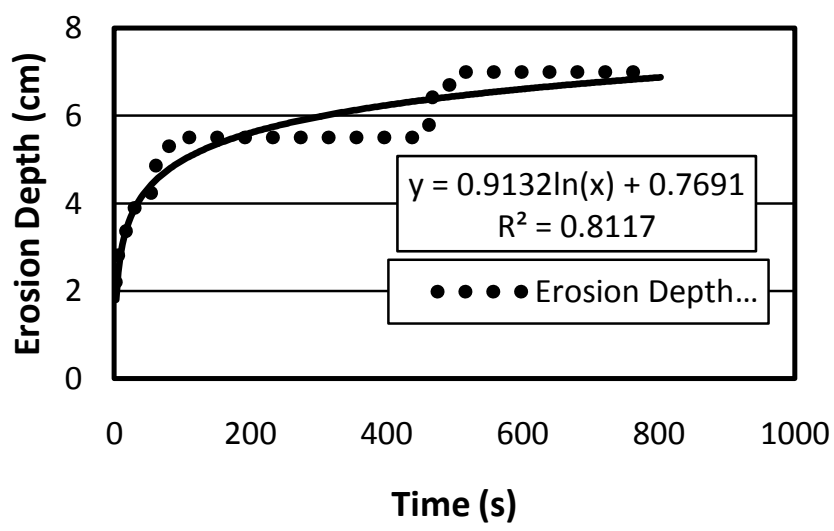

Fig. 6 Sample graph in order to show $k_{d}$ 
days; the depths in Fig. 6 were found using logarithmic curve fitting. Therefore from Fig. 6 it is found that $D_{e}=.1535 \mathrm{~m}$

Data known from UMETB:

$\theta=$ angle that water strikes soil $=90^{\circ}$

$y_{o}=$ plunging water width $=.003 \mathrm{~m}$

$u_{o}=$ velocity of water $=6 \frac{\mathrm{m}}{\mathrm{s}}$

$v=$ viscosity of water $=1.004 \times 10^{-6} \frac{\mathrm{m}^{2}}{\mathrm{~s}}$

$\rho=$ density of water $=1000 \frac{\mathrm{kg}}{\mathrm{m}^{3}}$

Computed Numbers

$$
\begin{gathered}
C_{d}=\sqrt{5.5(1+\cos \theta)}=2.345 \\
D_{p}=C_{d}^{2} y_{0}=2.345^{2} * 0.003=0.0165 \mathrm{~m}
\end{gathered}
$$

$\tau_{o}=C_{d}^{2} C_{f} \rho u_{0}^{2} \frac{y_{o}}{D}$

$=2.345^{2}(0.0029)(1000)\left(6^{2}\right) \frac{.003}{.055}=31.31 \mathrm{~Pa}$

$$
D_{e}=0.1535 \mathrm{~m}
$$

$\tau_{c}=\frac{D_{p}}{D_{e}} \tau_{e}=\frac{.0165}{.1509} * 31.31=3.42 \mathrm{~Pa}$

Using a data point in Fig.6 when time is $200 \mathrm{sec}$, and using $t_{o}, t_{c}$, and $k_{d}$ is computed as follows.

$$
k_{d}=0.000024311 \frac{m^{3}}{N^{*} \sec }
$$

Since most soil parameters such as density, shear strength, and water content vary with depth; the detachment coefficient $k_{d}$ should also vary with depth. This was accomplished by analyzing the erosion behavior at time intervals of 2 seconds, and calculating a $k_{d}$ value for each time interval, in doing so it allows for the calculation of a non-constant $k_{d}$ value.

\section{RESULTS AND ANALYIS}

Bare Soil: The representative sample that was chosen for comparison was F50S50, which has 50\% fines and 50\% sand, and a degree of compaction at
$83 \%$. The primary reason for this selection is that this sample shows quite low resistance to erosion in previous studies [Jang, 2010]. This is illustrated in Fig. 7. In principle, if a chemical or a plant can control erosion for this sample, it should be able to decrease erosion in other samples with higher clay percentages and degrees of compaction. The computed final erosion depth, or equilibrium depth $\left(D_{e}\right)$, was found to be $.494 \mathrm{~m}$ when time is equal to 100 days; this is illustrated in Fig. 8. The actual equilibrium depth would be slightly higher when time is equal to infinity; however, for analytical calculations the time was assumed to be 100 days for simplicity.

POSS Treated Samples: There were two tests conducted for POSS samples because there were two different types of POSS chemicals (SO1455 and SO1458), and the results along with bare soil can be found in Fig. 9. The same clay content and degree of compaction were used for the POSS samples (F50S50 and DOC 83\%) and bare soil samples. Both treated specimens showed a substantially higher resistance to erosion than the

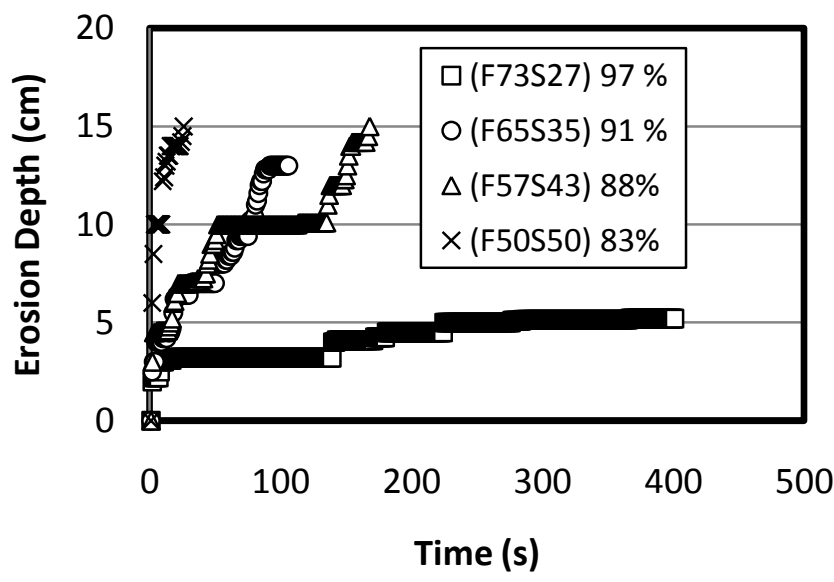

Fig. 7 Erosion Depth vs. Time relationship for bare soils

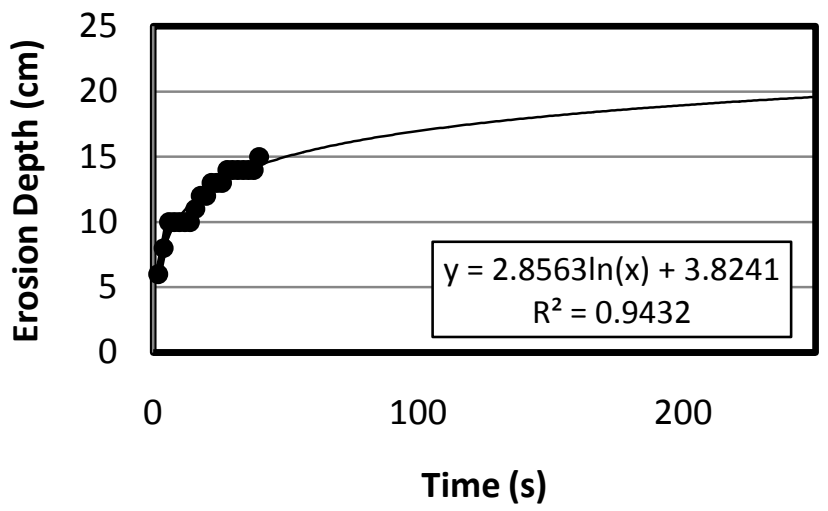

Fig. 8 Equilibrium Depth Equation 


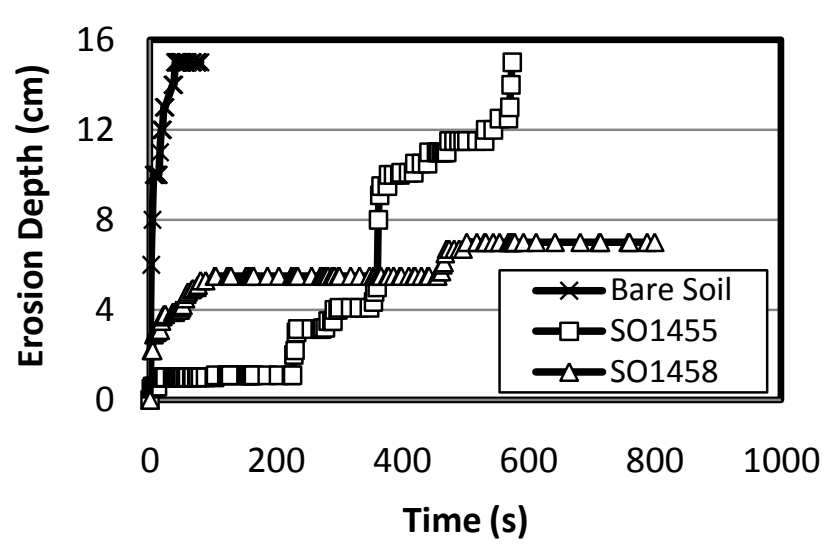

Fig. 9 Graphical Comparisons of POSS

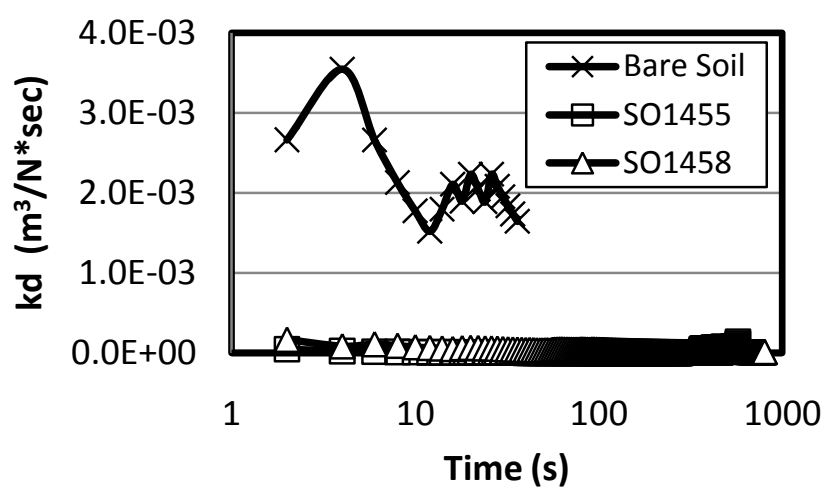

Fig. 10 Comparison of $k_{d}$ values for all POSS

samples

bare soil. However, SO1458 showed higher erosion depth initially, but it showed lower final erosion depth than SO1455. To compare the erosion resistance of samples in a more quantitative manner, the erosion rate coefficient was computed and compared in Fig. 10, which shows that POSS treated samples have a much lower $\left(k_{d}\right.$ of bare soil $\approx 2.0$ E- $03 \mathrm{~m}^{3} / \mathrm{N}^{*} \mathrm{sec}, k_{d}$ of POSS treated soil $\approx 2.0 \mathrm{E}-05$ $\mathrm{m}^{3} / \mathrm{N}^{*} \mathrm{sec}$ ) erosion rate coefficient when compared to bare soil.

To investigate engineering reasons for these findings, water content of test samples are compared. Following the submersion, the POSS samples appeared to be less water saturated compared to the bare soils. Figure 11 shows that POSS treated samples decreased the water content an average of $25 \%$, meaning that POSS smeared into the substantial portion of pore spaces and provided additional adhesion that may contribute to the higher erosion resistance. At a deeper depth, however, POSS samples showed about the same or higher water content at the bottom, indicating that POSS might not penetrate to deeper depths and erosion resistance might not be improved. Therefore,

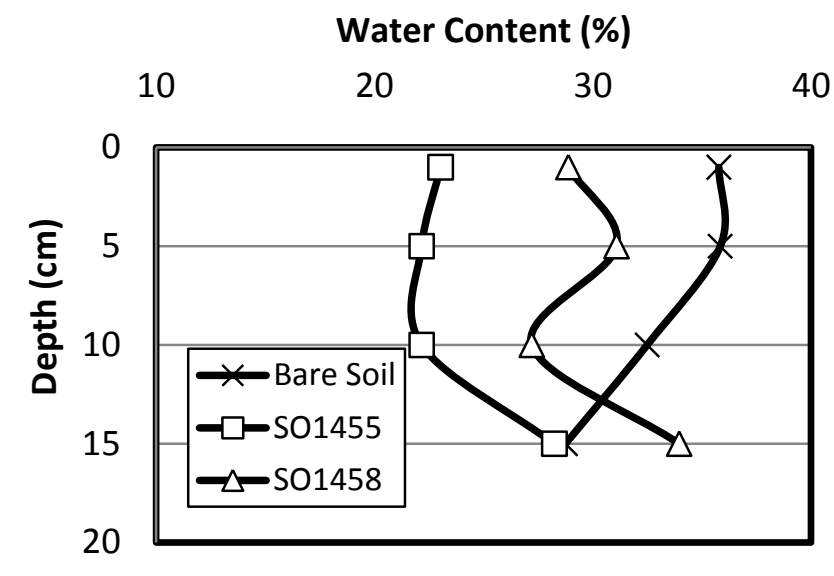

Fig. 11 Water Content Comparisons for POSS

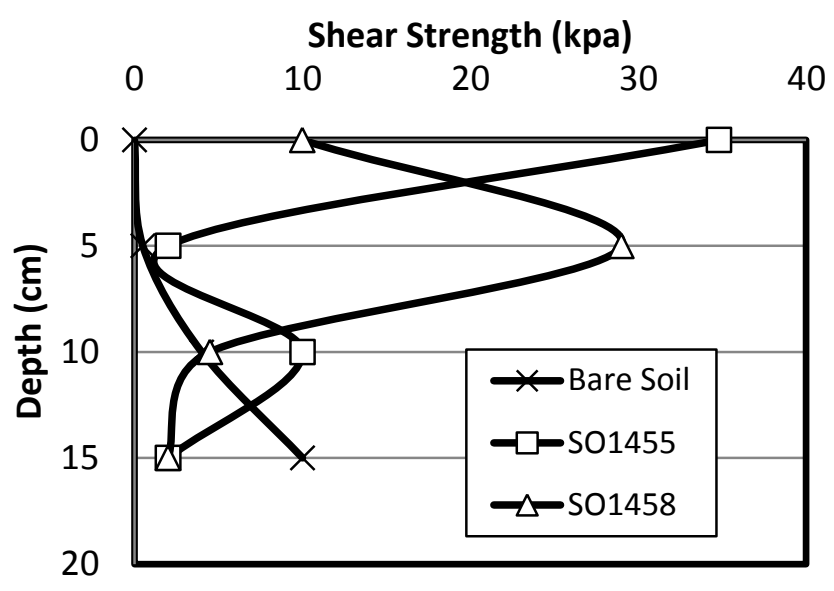

Fig. 12 Shear Strength of POSS samples

the soil might behave more like bare soil than reinforced soil at deeper depths.

Comparing the water contents of SO1455 and SO1458 at shallower depth (less than $10 \mathrm{~cm}$ depth), it can be seen that SO1458 has lower water content, indirectly indicating the higher POSS content, and higher erosion resistance. But this water content plot does not explain why SO1458 showed lower erosion resistance initially. Therefore, strength tests were conducted for test samples.

The shear strength of the POSS samples was measured by the miniature vane shear test apparatus. The results seen in Fig. 12 show the shear strength of POSS samples. Without POSS, the shear strength at the surface to $2 \mathrm{~cm}$ depth is very close to zero; however, POSS increases the shear strength at the surface substantially, which is also the point of impact for plunging water. After that, the shear strength was reduced to approximately the same level as that of the bare soil at deeper depths. This may explain why POSS treated samples show (particularly SO1455) quite high erosion rate 


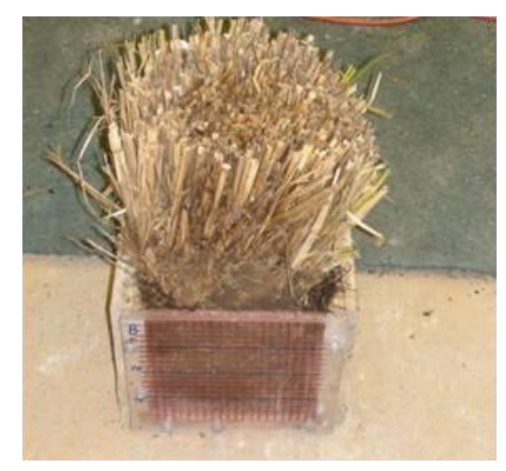

Fig. 13 Vetiver stems after erosion testing

coefficients for prolonged time periods. From Fig. 12 , it shows that the initial lower erosion resistance for SO1458 is mainly due to the lower shear strength of surface layers. As erosion progressed, the water needed to erode higher strength layer, and it showed higher erosion resistance. Therefore, it seems that shear strength provide better indicator than water content to predict the erosion behavior of soils.

Vetiver Plant: The Vetiver proved to be very effective in reducing the erosion of soil. It was so effective that currently no graphs, tables, or data can be obtained for the Vetiver because no erosion occurred. The Vetiver plant used in the experiment was grown for 12 years; and no quantitative data was available. Two separate tests were conducted. The first test, conducted with $10 \mathrm{~cm}$ of stem and root system, showed no recordable erosion.

Test results can be seen in Fig. 13. The second test was conducted on the root system only with the stems completely removed. No visible erosion was noted. Test results are shown in Fig. 14. From the figures, it can be seen that no measurable erosion occurred for either the root and stem together or the roots only in Vetiver samples. The plunging water seemed not to have reached further than the root system of the Vetiver. The structure of the plant (root system and grass stems) also held up well after being exposed to plunging water. Since the water never reached past the Vetiver stems to the actual soil, no data collection could be made. Therefore, the Vetiver proved effective in enhancing erosion resistance.

\section{CONCLUSION}

Erosion caused by plunging water caused extensive damage, in the New Orleans area during Hurricane Katrina. This research focused on reducing erosion through ground modification: erosion mitigation performance of POSS and Vetiver were assessed. Applying the previously

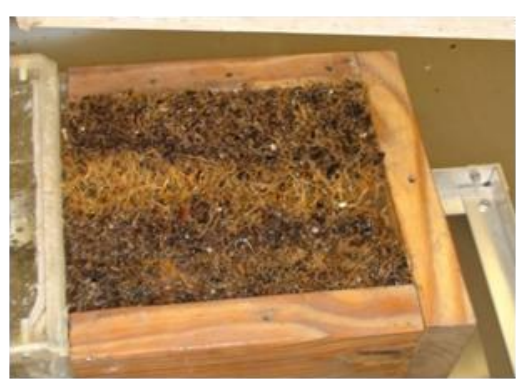

Fig. 14: Vetiver roots after erosion testing

developed excess shear stress concept and laboratory tests, all soil samples were evaluated by how effective each sample was at reducing erosion. From the results the following conclusions could be made:

1. POSS reduced erosion rate significantly $\left(\left(k_{d}\right.\right.$ of bare soil $\approx 2.0 \mathrm{E}-03 \mathrm{~m}^{3} / \mathrm{N}^{*} \mathrm{sec}, k_{d}$ of POSS treated soil $\approx 2.0 \mathrm{E}-05 \mathrm{~m}^{3} / \mathrm{N}^{*} \mathrm{sec}$. Shear strength was increased and water content was decreased due to POSS filling the voids in the soil samples.

2. POSS seemed to be effective only to a depth of about 9-12 cm; after erosion reached this depth; samples exhibited the similar erosion characteristics to bare soils. It is thought that this condition is due to POSS only penetrating the soil samples to this depth. However, it should be noted that POSS can easily be applied to field soils by simply spraying the liquid.

3. The Vetiver proved to be the quite effective. No recordable amounts of erosion occurred. Due to the dense vegetation and root system, water was unable to penetrate into soil samples.

4. The Vetiver would be cost effective and relatively easy to apply to soil along earthen levee systems. However, it may take substantial time to establish and grow Vetiver.

Suggested future work includes determining the erosion limit of Vetiver; this includes increasing the flow rate and water width thickness to reach maximum capacity of Vetiver. Also, testing different ages of Vetiver, because the density of the plant with increase with age. In addition, field investigation of the applicability of both POSS and Vetiver; full scale testing of the effects of both modifiers to ensure adequate erosion resistance. This includes planting Vetiver on a given levee system and monitoring the growth with respect to time. In addition, application methods for POSS should be tested such as: spraying methods, quantity of POSS, and sprayed coverage area. 


\section{ACKNOWLEDGMENT:}

This research was supported by funding received from the Department of Homeland Security-sponsored Southeast Region Research Initiative (SERRI) at the Department of Energy's Oak Ridge National Laboratory, USA. We also thank the COE New Orleans Office for granting permission to take samples. In addition, we also would like to thank Dr. Gregg Henderson at LSU, and Dr. Bruce $\mathrm{Fu}$ at Hybrid Plastics Co. for supplying Vetiver and POSS, respectively.

\section{REFERENCES}

Briaud, J. -L., Ting, F. C. K., Chen, H. C., Cao, Y., Han, S. W. and Kwak, K. W., (2001): Erosion Function Apparatus for Scour Rate Predictions, Journal of Geotechnical Engineering, Vol. 127, No. 2, February 2001, pp. 105-113, American Society of Civil Engineers, Reston, Virginia, US

Briaud, J. -L., Ting, F. C. K., Chen, H. C., Gudavalli, R., Perugu, S. and Wei, G., (1999): SRICOS: Prediction of Scour Rate in Cohesive Soils at Bridge Piers, Journal of Geotechnical Engineering, Vol. 125, No. 4, April 1999, pp. 237-246. American Society of Civil Engineers, Reston, Virginia, US

IPET (Interagency Performance Evaluation Taskforce) (2007): Performance evaluation of the New Orleans and Southeast Louisiana Hurricane Protection System. U.S. Army Corps of Engineers, https://IPET.wes.army.mil.
Song, C. R., Kim, J., Wang G. and Cheng, A. H-D. (2009): Reducing erodibility of earthen levee using engineered floodwall sections, Journal of Geotechnical Engineering Division, ASCE, submitted for publication

Hengchaovanich, D. and Nilaweera, N. S. (1996): An assessment of strength properties of vetiver grass roots in relation to slope stabilization. Proc. First Int. Vetiver Conf. Thailand, pp. 153-158.

Jang, W. (2010): Erosion Study of New Orleans Levee Soils Subjected to Plunging Water, Ph. D. Dissertation, University of Mississippi, 295 p.

Jang, W., Song, C. R., Kim, J., Cheng, A. H. -D. and Al-Ostaz, A. (2010): Erosion Study of New Orleans Levee Materials Subjected to Plunging Water

Hanson, G. J., Robinson K. M., Cook K. R., (2002): Scour Below an Overfall: Part II. Prediction, Transaction ASAE Vol. 45 (4), pp. 957-964.

Stein, O. R. and Nett, D. D. (1997): Impinging Jet Calibration of Excess Shear Sediment Detachment Parameters, Transactions of the ASAE, Vol. 40 (6), pp. 1573-1580.

Stein, O. R., Julien, P. Y. and Alonso, C. V. (1993): Mechanics of jet scour downstream of a headcut, Journal of Hydraulic Research of IAHR, Vol. 31 (6), pp. 732-738.

Vroman, N. D. (2008): Embankment Spec., Personal Communication. 